\title{
PSYCHOLOGICAL CONSTRUCT \& HUMAN RESOURCE DETERIORATION: HOW BURNOUT STRESS AND JOB INSECURITY TRIGGER TURNOVER INTENTION? A CROSS SECTIONAL STUDY FROM PAKISTAN \\ Muhammad Azeem Qureshi \\ Irfan Haider Shakri ${ }^{2}$ \\ Muhammad Tariq ${ }^{3}$ \\ Institute of Business \& Technology-IBT, Karachi.
}

\begin{abstract}
Purpose:- This study examines the impact of job burnout, occupational stress and perceived job insecurity which has been termed as a psychological construct; on turnover intention of the employees working in private healthcare sector of Pakistan. The psychological construct consists of bunch of variables which have not been measured so far in the proposed combination in any study conducted in Pakistan. This study examines the phenomenon in healthcare sector where under the influence of perceived job insecurity, working for long hour in consecutive shifts under chronic pressure for a long time causes occupational stress and burnout which leads to turnover intention that ultimately results in deterioration of human resource.

Methodology/Sampling:- This is cross-sectional, hypothesis testing research based on primary data collected from 5 renowned private sector healthcare institutions. The data was gathered through convenient sampling technique from 141 respondents comprising of doctors, nurses, administrative \& allied-health staff.

Findings:- The results suggest that the turnover intention is significantly positively influenced by job burnout, occupational stress and perceived job insecurity. Results also support that these conditions may lead loss of potential talent and hence failure in attainment of organizational long term objectives. Practical Implications:- Excessive workload, long working hours, intense working environment and demanding job tasks are the key factors that contribute to occupational stress and burnout. These conditions become more severe when accompanied by perceived job insecurity due to economic instability or elevated unemployment rate. This study can also be helpful to devise strategies to prevent or attenuate long term psychological and physical disorders of incumbents which ultimately affect the entire society.
\end{abstract}

Key Terms: Job burnout, Occupational stress, perceived job insecurity, Turnover intention

JEL Classification: I31, M10, M11

\footnotetext{
* The material presented by the author does not necessarily portray the viewpoint of the editors and the management of the Institute of Business \& Technology (IBT)

1. Muhammad Azeem Qureshi : azeem.qureshi@hotmail.com

2. Irfan Haider Shakri : Irfanshakri@gmail.com

3. Muhammad Tariq

(c) IBTJBS is published by the Institute of Business and Technology (IBT).

Main Ibrahim Hydri Road, Korangi Creek, Karachi-75190, Pakistan.
} 


\section{INTRODUCTION}

Retention of crucial talent has been regarded as a key ingredient of long term organizational success. Just like other resources, potential talent is the significant source of core competency for many organizations which ultimately leads to gain and maintain competitive advantage. Loss of potential talent results in the form of failure of long term goals' achievement and hence the ultimate vision gets blurred and goes more far away. Psychological resources of an employee get deteriorated gradually during the burn out process which results in prolonged workplace stress. Disequilibrium between the available resources and expected outcome by senior management produces the work burnout when employees are unable to cope with prevailing differences. It has been argued by many researchers that employees who can possibly become victim of burnout show impaired job performance and simultaneously are prone to serious health problems.Factors that trigger turnover intention are of significant concern and have captured attention of many management practitioners. The turnover intention ultimately leads to leaving the jobultimately; subject to availability of job opportunities in market. However this phenomenon varies from industry to industry or even organization to organization but its presence is likely to occur in the organizations hiving long working hours and consecutive shifts that disturb work-life balance of employees. Hospital industry especially in mega city like Karachi has huge burden of patients across the country. In spite of limited increase in medical facilities, health facilities are still insufficient to cater the need of both patients and medical staff including doctors, nurses and paramedical staff in Karachi. Tough schedule, intense environment and demanding job generate occupational stress and burnout and uncertainty about job prospects because of scarcity of employment opportunities trigger perceived job insecurity and thus these conditions may lead to turnover intention. The turnover intention may result in organizational malfunctioning in terms of loss of talent and unaccomplished objectives in long run. This study examines the causality of proposed independent variables (i.e. Occupational Stress, Job Burnout, and Perceived Job Insecurity) on the dependent variables (i.e. turnover intention) in healthcare sector of Karachi.

\subsection{Problem Statement}

Healthcare is a vastly growing sector yet the turnover of employees is on the higher side. Availability of trained workforce and lingering vacancy rates are the major challenges facing by the health care organizations. The impact is evident in workflow inefficiencies, dissatisfaction level among patients \& staff and delays in patient care, all these elements can cause substantial negative effects on patient safety and quality of care. In addition, the astounding administrative costs created by an ephemeral work force have shown signs of threats to financial viability of any health care organizations. At a glance the problem is correlated with the extremely low availability of talented resources as oppose to the aggressive headhunting amongst competing healthcare organizations. However, the real cause is annexed to the said problem; the available / onboard human resource needs to work rigorously to fill the human supply gap which is resulting in burnout, stress and at some place as job insecurity. Many healthcare organizations do not recognize that the high turnover is because of psychological and physical exhaustion and occupational stress. The motive of this study is to find out the 
Psychological Construct \& Human Resource Deterioration: How Burnout Stress and Job Insecurity trigger Turnover intention? A Cross Sectional Study from Pakistan

impact of job burnout, occupational stress and perceived job insecurity on turnover intention.

\subsection{Research Objectives}

1. To find out the impact of occupational stress on turnover intention.

2. To determine the impact of burnout on turnover intention.

3. To examine the effect of perceived job insecurity on turnover intention.

\section{LITERATURE REVIEW}

\subsection{Burnout}

Many employees experience the great deal of job strain that may include exhaustion, job-detachment, disengagement and health complaints due to demanding job and higher expectations (Schaufeli\&Greenglass, 2001).Burnout is considered as an outcome resulting from inability to deal with work-related stress, degenerated social relations, long-term exhaustionand diminished decreased interest in job (Sacco, 2011). The concept of "Burnout" has been in spot light of numerous researchers in the context of organizational psychology since last decade. The concept or construct has been conceptualized through three components in profuse literature. These components include "emotional exhaustion" which refers to feelings of depletion or loss of physical and emotional resources which includes (1) job control (2) access to information (3) supervisory support (4) innovative school climate and (5) social climate (Hakanen et al, 2006), "Cynicism or depersonalization" which pertains to de-motivation, distant and insensible attitude towards one's job and "Lack of professional efficacy or reduced personal accomplishment" which is developed in response to chronic occupational stress (Maslach et al., 2001).

Long-term mismatch with between job-demand and worker's resources or capacity has been found to be contributory factor of burnout (Hobfoll\&Shirom, 2001), therefore the concept of burnout is not supposed to be confused with job-related stress as the burnout is the result of enduring adaptive failure (Schaufeli\&Buunk, 2003). High work load, as well as lack of participation and social support at work also increases the risk of burnout (Ahola et al., 2006). The Job-demand and resource (JD-R) model proposes that burnout and reduced work engagement are fostered by high job demands and a lack of job resources (Hakanen et al, 2006).

\subsection{Occupational stress}

Occupational stress is defined as "A disruption of the equilibrium of the cognitiveemotional-environmental system by external factors" (Lazarus \&Folkman, 1984). It is evident that occupational stress stems from two sources, (1) job demand and (2) lack of job resources (Pienaar and Rothmann, 2003). Occupation stress is also descried as "The experience of negative emotions such as anxiety, frustration, tension, anger, or depression, in response to the demands and pressures they face in their work" (Kyriacou, 2015). Similar concept has been framed previously through another definition which defines job-related stress as "The experience by an employee of unpleasant, negative emotions, such as anger, anxiety, tension, frustration or depression" (Kyriacou, 2001). Depression, in response to the demands and pressures they face in their work Occupational 
stress has a significant impact on job performance, job satisfaction and turnover intention. The findings have demonstrated same significant results irrespective of the country origin whether developed or under developed countries (Minget al, 2015). Stress occurs when individual realizes that the amount of pressures or whatever the situation demands is broader that he or she can cope with; and if this situation prevails for a long time without any breaks than that individual might face behavioural, physical and mental problems. Work environment, management support and workload are the key variables to determine how much the employee is physically and mentally stressed (Bashir \&Ramay, 2010).

\subsection{Job Insecurity}

The concept of job insecurity has been subject to changes in meanings in last decades. Job insecurity was taken as motivator rather than as a stressor during the mid 1960s and 1970s (Hackman \& Oldham, 1975). In the mid-1980s, Greenhalgh and Rosenblatt (1984) were among the firsts who pointed job insecurity in a larger hypothetical context who, with their hypothetical model, summarized the meanings of job insecurity and explained on the potential causes, effects, also hierarchical outcomes of the phenomenon. They characterized job insecurity as "perceived powerlessness to maintain desired continuity in a threatened job situation and that job insecurity is based on the individual's interpretation of the immediate work environment and perception regarding that environment" (1984, p. 438).

Subjective or perceived job insecurity has been linked to negative behavior towards one's job and organization, and hesitance to remain attached with the organization (Näswall and De Witte, 2003; Sverke et al., 2002). It has been proposed by many researches that subjective job insecurity is more prone to mental health illness as compared to biological and physical negative consequences (Mohr, 2000). There are evidences that the anxiety as the result of job insecurity may give rise to family conflicts (Westman et al., 2001). Organizational cynicism instigates job insecurity perception and turnover intention along with moderating role of demographic characteristics. This issue is however debatable as different finding have supported or disproved their moderating role (Çinar et al, 2014).

Employees tend to move from insecure work environment to secure work environment. Threat to job, just like any stressor, is associated with higher level of turnover intentions (Burke \& Nelson, 1998). Significant relationship between job insecurity and turnover intention has been observed which is partially mediated by Occupational well-being. Further, at the individual level the lower level of well-being creates stronger negative effect of job insecurity (Mauno et al, 2014). Further Cynicism (distrust) influences turnover intention (Shahzad\&Mehmood, 2012). Similar findings have been reported in a study proposing that subjective job insecurity cab be induced by lower well-being and unemployment rate (Scwarz, 2012).

\subsection{Turnover intention}

Meyer \& Allen (1984) defined turnover intention as "an employee's intention to quit his or her present job or organization". According to Carmeli\& Weisberg (2006) "It starts thinking about leaving an organization, finding another alternative, and finally having turnover intent". Employees may involuntarily stay in their job in the absence of available job opportunities but change in attitude and decreased job performance 
Psychological Construct \& Human Resource Deterioration: How Burnout Stress and Job Insecurity trigger Turnover intention? A Cross Sectional Study from Pakistan

may occur in the form of unfavorable outcome (Lingard et al, 2003). Even if employees stay within organization, their productivity and effectiveness at work suffers because of burnout (Maslach et.al, 2001).

Turnover intention has been found to be significantly associated with burnout (Ducharme\& Roman, 2006). Similar findings support this argument in another research conducted in Pakistan where results suggest that job-burnout triggers turnover intention (Jamal, 2007). Another study conducted in Turkey investigated the relationship between burnout and turnover intention on top, middle and lower level managers revealed that employees who reported that they were more exhausted, more cynical, feel less professional efficacy had more turnover intention their organization (Özbag a et al, 2014). Depression, anxiety, memory impairment, sleep disturbance, and neck pain are the most commonly observed health problems amongst the employees who are facing the high level of job burnout and in some cases a risk factor for cardiovascular diseases as well (Bakker \& Costa, 2014). Subsequently, lateness, absence, or turnover are expected behaviours by burn the burned-out employees (Maslach et al., 2001). Supporting evidence has also been reported in a study measuring the impact of jobburnout and job satisfaction on turnover intentionon Chinese nurses in healthcare sector. Moderate level of emotional exhaustion, depersonalization and elevated levels of reduced personal accomplishment has been reported by nurses leading to turnover intention (Zhang et al, 2014).

\subsection{Statement of hypothesis}

H1: There is a significant impact of occupational stress on turnover intention.

$\mathrm{H} 2$ : Job burnout significantly affects turnover intention.

H3: Perceived job insecurity significantly impactsturnover intention.

\subsection{Conceptual framework}

See Fig. in Appendix

\section{RESEARCH METHODOLOGY}

The current study is cross-sectional, hypothesis testing primary research conducted at Karachi. Regression analysis has been performed to measure causal relationship between proposed independent and dependent variables. All statistical tests including reliability analysis to assess internal consistency and reliability of the data and simple linear regression have been performed on SPSS v17. All the assumptions of causal relation including "Temporal sequence", "Concomitant variation" and "non-spurious association" are supported by the data.

\subsection{Participants}

Five organizations were identified from private healthcare sector in Karachi to conduct this study. A sample of 141 staff from different cadres like doctors, nursing, administrative and allied-health staff were drawn as a sample from the identified organizations. All the data was gathered through convenience sampling technique due to access and availability of subjects. A questionnaire consisting of 53 questions addressing all proposed variables was developed and was distributed amongst respondents of all 


\subsection{Measures}

Occupational Stress(OS) was assessed through questionnaire developed by American Institute of Stress (AIS). Subscale of stress as comprised of ten items (e.g. Most of the time I feel I have very little control over my life at work.) All the items were scored on a five-point Likert scale ranging from 1 ("strongly disagree") to 5 ("strongly agree"). Reliability analysis (a) was 0.92 on all ten items.

Job burnout (JB) was measured through MaslachRevised Burnout Inventory - MBIGS (Maslach\& Jackson, 1996). Three subscales (exhaustion, cynicism and efficacy) were used to determine the level of burnout. Subscales of exhaustion and cynicism were comprised of four items each and effectiveness at work place (efficacy) was comprised of 6 items. All the items were scored on a five-point Likert-scale ranging from 1 ("strongly disagree") to 5 ("strongly agree"). The reliability (a) of the variables were 0.91 (exhaustion \&cynicism) and 0.93 (efficacy).

Perceived Job Insecurity (PJI): Subjective approach has been used to measure job insecurity (De Witte, 2003; Mohr, 2000). Job insecurity has been measured by using five items on five-point Likert scale (from $1=$ strongly disagree to $5=$ Strongly Agree). $(a=89.6)$.

Turnover intention (TI) was measured on five point Likert scale (from $1=$ strongly disagree to 5 = Strongly Agree) by two items proposed by Schalkwyk et al, 2010, (a $=75.2$ ).

\section{DATA ANAL YSIS}

Regression analysis has been performed to measure cause and effect among proposed dependent and independent variables as results depicted in Table 1 to Table 3 (see Appendix).

\subsection{Discussion}

The regression results reported in the table above indicates that all of the independent variables are positively related to the dependent variableand all of the estimated parameters are statistically significantly different from zero. Since the criterion for model fits the data well is the difference between models's predicted values and observed values should be small and unbiased. In our case the goodness of the model fit is significant $(\mathrm{R} 2=0.653)$. It can also be concluded from correlation coefficient $(\mathrm{R}=0.808)$ that Turnover intention is positively related to JB, OS and PJI. Since the value of $p=$ 0.000 in ANOVA table, the relationship between proposed IV (JB, OS, PJI) and DV (ITL) is highly significant.Values of Beta-Coefficients show that ITL is being explained 45\% through OS, 33\% through PJI and 17\% through JB. So, all the null hypotheses have been rejected through the statistical analysis. It has been proved through the interpretation of the above data analysis, higher levels of JB, OS and PJIcreate significant positive impact on ITL.

\section{CONCLUSION}

Based on the data collected from 141 respondents consisting of doctors, nurses, 
Psychological Construct \& Human Resource Deterioration: How Burnout Stress and Job Insecurity trigger Turnover intention? A Cross Sectional Study from Pakistan

administrative and allied-health staff from five different private healthcare organizations in Karachi, we conclude that the results support the findings of previous studies conducted in different countries other than Pakistan. The phenomenon of turnover intention (ITL) has been proved to be valid in the case of healthcare sector of Karachi as well. The impact of JB, PCI and OS has positive significant impact in ITL. Thus all three null hypotheses $(\mathrm{H} 0)$ against the proposed alternative hypothesis (HA) have been rejected. The findings support the validity of the phenomenon irrespective of the level or department of the staff of healthcare sector and prevalence of ITLimpacted by JB, $\mathrm{OS}$ and PJI.

\subsection{Recommendations}

- $\quad$ Rescheduling of working hours and shift scheme amendment should be made to maintain work-life balance of employees of healthcare sector to avoid job burnout, occupational stress and perceived job insecurity.

- Job insecurity perception should be eliminated by encouraging supportive environment where employees feel secure with respect to their jobs in order to retain potential talent to achieve long term organizational objectives.

- $\quad$ Occupational stress not only affects the job performance but also the psychological and physical well-being of employees, leading to work-family conflicts and increased economic cost for both employees of healthcare sector and their customers (patients).

- $\quad$ Occupational stress and job burnout particularly in doctors and nurses can result disastrous and catastrophic effects on patients, so drastic steps should be taken to avoid these unwanted outcomes.

\subsection{Future Scope of the study}

Further evidence from different provinces can be helpful to apprehend the concept more precisely and to determine intervening effect of extraneous variables such as age, gender and other demographic factors as moderator to establish whether these moderators either change the direction or strengthen or make relationship weaker between IV(OS, JB, PJI) and DV (ITL). I addition, mediating role of variables such as organizational commitment, organizational citizenship behavior can be more supportive to encompass all related aspect of the present research.

\section{ACKNOWLEDGEMENT}

First of all with a profound gratitude, we are thankful to Almighty Allah forgiving us success, knowledge and understanding without which we would not been capable of completing this research paper.

We are also profoundly grateful to all our family members whose endurance and understanding have played a significant role in our success by sacrificing the important family time and supporting us all over the research work.

We are finally thankful to the editor, reviewers and IBT specially who provided us with the opportunity to publish our research paper in this esteemed journal. 
Ahola, K., Honkonen, T., Kivimäki, M., Virtanen, M., Isometsä, E., Aromaa, A., et al. (2006). Contribution of burnout to the association between job strain and depression: The Health 2000 Study. Journalof Occupational and Environmental Medicine, 48, 1023-1030.

Bashir, U., Ramay, M. I. (2010). Impact of Stress on Employees Job Performance: A Study on Banking Sector of Pakistan. International Journal of Marketing Studies. 2(1), 122-126.

Burke, R. J., \& Nelson, D. (1998). Mergers and acquisitions, downsizing, and privatization: A North American perspective. In M. K. Gowing, J. D. Kraft, \& J. C. Quick (Eds.), The new organizational reality: Downsizing, restructuring, and revitalization (pp. 21-54). Washington, DC. American Psychological Association.

Carmeli, A., Meitar, R., \& Weisberg, J. (2006). Self-leadership skills and innovative behavior at work. International Journal of Manpower, 27(1), 75-90.

Chao, M., Jou, R. ,Liao, C.\&Kuo, C.(2015). Workplace Stress, Job Satisfaction, Job Performance, and Turnover Intention of Health Care Workers in Rural Taiwan. Asian Pacific Journal of Public Health, 27 (2).

Çinar, O., Karcioglu, F., Aslan, I. (2014). The relationships among Organizational Cynicism, Job Insecurity and Turnover Intention: A Survey Study in Erzurum/Turkey. Procedia - Social and Behavioral Sciences, 150, 429 - 437.

De Witte, H., \&Näswall, K. (2003). "Objective" vs. "Subjective" job insecurity: Consequences of temporary work for job satisfaction and organizational commitment in four European countries. Economic and Industrial Democracy, 24, 209-312.

Greenhalgh, L., and Rosenblatt, Z. (1984). Job insecurity: Toward conceptual clarity. Academy of Management Review, 3, 438-448.

Hackman, J. R., \& Oldham, G. R. (1975). Development of the Job Diagnostic Survey. Journal of Applied Psychology, 60, 159-170.

Hakanen, J. J., Bakker, B. A. \&Schaufeli, B. W. (2006). Burnout and work engagement among teachers. Journal of School Psychology, 43, 495 - 513.

Hobfoll, S.E., \&Shirom, A. (2001). Conservation of resources theory: Applications to stress and management in the workplace. In R.T. Golembiewski (Ed.), Handbook of organizational behavior (pp. 57-80) (2nd ed.). New York, NY: Marcel Dekker. Jamal, M. (2007). Burnout and self-employment: a cross-cultural empirical study. Stress and Health, 23(4), 249-256.

Knudsen, H. K., Ducharme, L. J., \& Roman, P. M. (2006). Counselor emotional exhaustion and turnover intention in therapeutic communities. Journal of Substance Abuse Treatment, 31, 73-180.

Kyriacou, C. (2001), Teacher stress: direction for future research.Educational Review, 53(1), 27-35.

Kyriacou, C., (2015). Teacher Stress and Burnout: Methodological Perspectives. International Encyclopedia of the Social \& Behavioral Sciences, 2(24). Lazarus, R.S. \&Folkman, S. (1984). Stress, appraisal and coping. New York: Springer-Verlag.

Lingard, L., Garwood, K., Schryer, C.F., Spafford, M.M. (2003), A certain art of 
Psychological Construct \& Human Resource Deterioration: How Burnout Stress and Job Insecurity trigger Turnover intention? A Cross Sectional Study from Pakistan

uncertainty: Case presentation and the development of professional identity. Social Science \& Medicine, 56(3),603-616.

Maslach, C., Jackson, S. E., \&Leiter, M. P. (1996). MaslachBurnout Inventory manual (3rded.). Palo Alto, CA: Consulting Psychologists Press.

Maslach, C., Schaufeli, W.B., \&Leiter, M.P. (2001). Job burnout. Annual Review of Psychology, 52(1), 397-422.

Maslach, C., Schaufeli, W.B., \&Leiter, M.P. (2001). Job burnout. Annual Review of Psychology, 52(1), 397-422.

Mauno, S., Cuyper, N., Tolvanen, A., Kinnunen, U. \&Makikangas, A. (2014). European Journal of Work and Organizational Psychology, 23 (3), 381-393.

Meyer, J. P. \& Allen, N. J. (1984). Testing the "side bet theory" of organizational commitment: Some methodological considerations. Journal of Applied Psychology, 69, 372-378.

Mohr, G. B. (2000). The changing significance of different stressors after the announcement of bankruptcy: A longitudinal investigation with special emphasis on job insecurity. Journal of Organizational Behavior, 21, 337-359.

Özbag a, G. K., Ceyhunb, G. C., Çekmecelioglu, H. G. (2014). The Moderating Effects of Motivating Job Characteristics on the Relationship between Burnout and Turnover Intention. Procedia - Social and Behavioral Sciences, 150, 438 - 446.

Pienaar, J. \&Rothmann, S. (2003, September). Job stress in the South African Police Services. Paper presented at the 15th Conference of the South African Institute for Management Scientists, Potchefstroom.

Sacco, M. D. F. 2011. "The Psychophysiological Impact of Burnout in Special and General Education Teachers." Master's thesis, Auburn University.

Schaufeli, W. B., \&Buunk, B. P. (2003). Burnout: an overview of 25 years of research and theorizing. In M. J. Schabracq, J. A. M. Winnubst, \& C. L. Cooper (Eds.), Handbook of work and health psychology (pp. 383-425).

Schaufeli, W.B., \&Greenglass E.R. (2001). Introduction to special issue on burnout and health. Psychology and Health, 16, 201-510.

Schwarz, P. (2012) Neighborhood effects of high unemployment rates: welfare implications among different social groups, The Journal of Socio-Economics, 41, 180-88.

Shahzad, A. and Mahmood, Z. (2012). The mediating-moderating model of organizational cynicism and workplace deviant behavior: Evidence from banking sector in Pakistan. Middle-East Journal of Scientific Research, 12(5): 580-588.

Sverke, M., Hellgren, J., \&Näswall, K. (2002). No security: A meta-analysis and review of job insecurity and its consequences. Journal of Occupational Health Psychology, 7, 242-264.

Van Schalkwyk, S., Du Toit, D.H., Bothma, A.S., \&Rothmann, S. (2010). Job insecurity, leadership empowerment behavior, employee engagement and turnover intention in a petrochemical laboratory. SA Journal of Human Resource Management, 8(1), 234-241. DOI: 10.4102/sajhrm.v8i1.234.

Westman, M., Etzion, D. and Danon, E. (2001), "Job insecurity and crossover of burnout in married couples", Journal of Organizational Behavior, 22 (5), 467-81.

Zhang, L., You, L., Liu, K., Zheng, J., Fang, J., Lu, M., Lv, A., Ma, W., Wang, J. W. S., Xue Wu, Zhu, X. \& Bu, X. (2014). The association of Chinese hospital work environment with nurse burnout, job satisfaction, and turnover intention. Nursing Outlook, 62(2), 128-137. 


\begin{tabular}{|l|l|l|l|c|}
\hline Model & R & R Square & Adjusted R Square & Std. Error of the Estimate \\
\hline 1 & $.808 \mathrm{a}$ & .653 & .645 & .386 \\
\hline
\end{tabular}

a. Predictors: (Constant), Perceived Job Insecurity, Burnout, Occupational Stress

Table 2 ANOVAb

\begin{tabular}{|l|l|r|r|r|l|r|}
\hline Model & Sum of Squares & \multicolumn{1}{c|}{ df } & Mean & Square & F & Sig. \\
\hline 1 & Regression & 38.292 & 3 & 12.764 & 85.883 & $.000 \mathrm{a}$ \\
& Residual & 20.361 & 137 & .149 & & \\
& Total & & 58.652 & 140 & & \\
\hline
\end{tabular}

a. Predictors: (Constant), Perceived Job Insecurity, Burnout, Occupational Stress

b. Dependent Variable: Turnover intention

Table 3 Coefficientsa

\begin{tabular}{|l|c|l|c|c|c|}
\hline \multirow{2}{*}{ Model } & \multicolumn{2}{|l|}{ Unstandardized Coefficients } & $\begin{array}{c}\text { Standardized } \\
\text { Coefficients }\end{array}$ & & \\
\cline { 2 - 6 } & $\mathrm{B}$ & Std. Error & Beta & $\mathrm{t}$ & Sig. \\
\hline (Constant) & .183 & .290 & .630 & .530 & \\
Burnout & .173 & .056 & .163 & 3.107 & .002 \\
Occupational Stress & .449 & .075 & .459 & 6.004 & .000 \\
Perceived Job & .328 & .075 & .341 & 4.368 & .000 \\
Insecurity & & & & & \\
\hline
\end{tabular}

a. Dependent Variable: Turnover intention

\section{Descriptive Analysis}

Statistics

\begin{tabular}{|c|c|c|c|c|c|}
\hline & & Ins_Name & Job_Cattegory & Gender & Age \\
\hline $\mathbf{N}$ & $\begin{array}{l}\text { Valid } \\
\text { Missing }\end{array}$ & $\begin{array}{c}141 \\
0\end{array}$ & $\begin{array}{l}141 \\
0\end{array}$ & $\begin{array}{l}141 \\
\mathrm{O}\end{array}$ & $\begin{array}{l}141 \\
0\end{array}$ \\
\hline $\begin{array}{l}\text { Mean } \\
\text { Percentiles }\end{array}$ & $\begin{array}{l}10 \\
20 \\
30 \\
40 \\
50 \\
60 \\
70 \\
80 \\
90\end{array}$ & & & & $\begin{array}{l}30.43 \\
25.00 \\
26.00 \\
27.00 \\
28.00 \\
29.00 \\
31.00 \\
32.00 \\
35.00 \\
37.00\end{array}$ \\
\hline
\end{tabular}

Job Category

\begin{tabular}{|ll|c|c|c|c|}
\hline & & Frequency & Percent & Valid Percent & Cumulative Percent \\
\hline Valid & Administrative & 30 & 21.3 & 21.3 & 21.3 \\
& Allied Health & 47 & 33.3 & 33.3 & 54.6 \\
Doctor & 27 & 19.1 & 19.1 & 73.8 \\
Nurse & 37 & 26.2 & 26.2 & 100.0 \\
Total & 141 & 100.0 & 100.0 & \\
\hline
\end{tabular}


Psychological Construct \& Human Resource Deterioration: How Burnout Stress and Job Insecurity trigger Turnover intention? A Cross Sectional Study from Pakistan

Gender

\begin{tabular}{|l|l|c|l|l|l|}
\hline \multicolumn{2}{|c|}{} & Frequency & PercentValid & Percent & Cumulative Percent \\
\hline Valid & Female & 64 & 45.4 & 45.4 & 45.4 \\
& Male & 77 & 54.6 & 54.6 & 100.0 \\
& Total & 141 & 100.0 & 100.0 & \\
\hline
\end{tabular}

Frequency Table

Ins_Name

\begin{tabular}{|l|l|c|c|c|c|}
\hline \multicolumn{1}{|c|}{} & Frequency & Percent & Valid Percent & Cumulative Percent \\
\hline Valid & $\begin{array}{l}\text { Aga Khan } \\
\text { University Hospital }\end{array}$ & 35 & 24.8 & 24.8 & 24.8 \\
\cline { 2 - 6 } & $\begin{array}{l}\text { Mamji Orthopedic } \\
\text { \& General Hos }\end{array}$ & 27 & 19.1 & 19.1 & 44.0 \\
\cline { 2 - 6 } & Patel Hospital & 25 & 17.7 & 17.7 & 61.7 \\
\cline { 2 - 6 } & $\begin{array}{l}\text { Trauma \& Orthopedic } \\
\text { Center }\end{array}$ & 25 & 17.7 & 17.7 & 79.4 \\
\cline { 2 - 6 } & $\begin{array}{l}\text { Ziauddin Medical } \\
\text { University }\end{array}$ & 29 & 20.6 & 20.6 & 100.0 \\
\cline { 2 - 6 } & Total & 141 & 100.0 & 100.0 & \\
\hline
\end{tabular}

Age

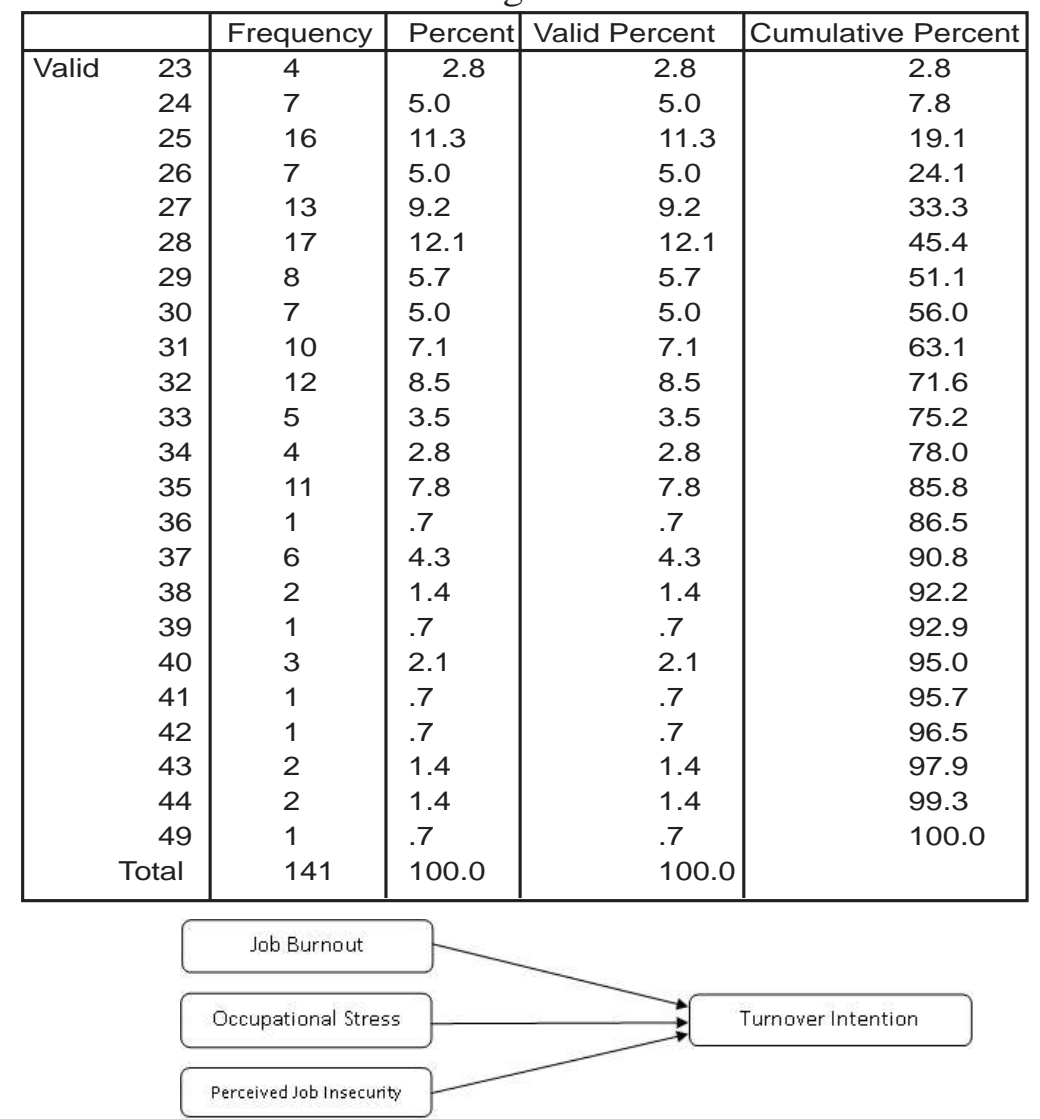

Figure No. 1 